\title{
The shock of lockdown on the spending on wine in the Iberian market: the effects of procurement and consumption patterns
}

\author{
ABSTRACT \\ Purpose \\ This study aims to provide a better understanding of the behaviour of wine consumers in a \\ completely new and unexpected setting, that is, a forced lockdown due to the Covid-19 pandemic. \\ It seeks to explain consumer decisions and the probability of changes occurring in wine \\ expenditure compared to a normal situation.

\section{Design/methodology/approach} \\ The empirical analysis, conducted on a representative sample of Iberian consumers and based on \\ the random utility theory, applies a multinomial logit model, setting the "usual" pattern of \\ expenditure as a baseline category.
}

\section{Findings}

The results show that the coronavirus pandemic could have changed alcohol drinking habits. Consumers generally spent less on wine during the lockdown, maybe due to the uncertainty regarding their future income and professional situation. Those who were more likely to spend more on wine increased their wine consumption during the lockdown, those who drank for romantic purposes, those who purchased less wine in supermarkets but more online, those who used a wine app, and those living in urban areas. The increased consumption of other alcoholic beverages also increases the probability of spending less than usual on wine. Additionally, the absence of specific reasons for drinking wine other than social purposes, such as wine and food pairing, its taste and relaxing effects, together with the previous consumption pattern, leads to a decrease in the probability of spending less per bottle.

\section{Originality}

This paper makes a significant contribution to the understanding of the determinants of wine consumption in a very abnormal setting, an imposed lockdown, and provides important policy implications. The findings show that managers and policymakers should pay attention to the different influences of variables related to behaviour and consumption patterns that may increase the demand for less expensive wines. Specifically, they should focus on new consumption patterns that may arise, adapt the supply chain, and define appropriate marketing strategies to fill new market segments. 


\section{Introduction}

Similarly to other industries and products, to reduce risk, wine producers must adapt their activities to evolving physical circumstances, such as climate change, consumer behaviour and purchasing habits, and other exogenous shocks resulting from changes in the markets, financial and even geopolitical crises. Unexpected shocks, such as economic or financial crises (Bor et al., 2013; Garbinti et al., 2020), earthquakes (Forbes and Wilson, 2018), and threats or terrorist attacks (Gergaud et al., 2018), may particularly affect consumer behaviour related to alcohol beverage consumption and purchasing patterns.

Over the last year, Covid-19 has emerged as a completely new public health issue, with a rapid transmission globally and without any medical solution, leading to massive lockdowns and affecting large populations on many levels, including psychological, social, political, and economic. Additionally, the wide coverage of Covid-19 in written, visual, and social media has increased levels of anxiety and fear among the public (Arpaci et al., 2020), affecting the level of utility achieved and both consumer spending patterns and willingness to pay for goods.

In Europe, Covid-19 was very severe in Italy, Spain, France, and Portugal in the early stages of the first wave. These countries are both large wine producers and consumer countries, and wine consumption forms part of their social habits (Anderson and Pinilla, 2018). Therefore, it is essential to know how wine consumers react in an abnormal situation, such as the lockdown (due to Covid-19), and how wine spending has been affected. Consequently, we can ask the following research question: How did the change in procurement and consumption patterns during the lockdown influence the probability of changes in wine spending? Finding the answer to this question is the main goal of this paper, which is focused on obtaining a greater knowledge of consumer behaviour in terms of the consumption of wine in an unusual environment and providing information that can be useful to the stakeholders in the wine industry. Specifically, the focus is to study consumer choice, paying particular attention to the change in the willingness to pay/spend (price segments) due to the lockdown.

The speed of the changes in consumer behaviour and the exceptional nature of the pandemic has turned the analysis of changes in consumer behaviour into a significant matter. The fact that the pandemic has gone on so long and not yet ended may also turn some of these temporary changes into actual new consumer habits.

Wineries, distributors, and other marketing agents have directly suffered the changes that lockdowns have caused in terms of consumption and in the price paid by consumers. Thus, this paper aims to provide evidence on these changes in consumption, their impact, and their expected time frame to improve the understanding of a new consumption model, the duration of which is still unknown.

The remainder of the paper is organised as follows. Section 2 presents the theoretical background of the article and the hypotheses to be tested. Section 3 includes a brief description of the sample, the variables used in the study and the econometric method used to address the issue. Section 4 consists of the model results and discussion. Finally, Section 5 concludes the paper.

\section{Theoretical background and hypothesis}


Consumer behaviour is one of the most interesting areas of research in social science. A review of the literature on this topic reveals that the focus is mainly on the way social, economic, and psycho-social changes and the importance of technology has affected consumer behaviour. (Peighambari et al., 2016; Szacka- Mokrzycka, 2015). Drinking is a consuming action involving an intrinsic relationship where the product is the core of the process. Wine consumption features a triple paradigm: utilitarian, symbolic and experiential, and we can identify different reasons behind consumption such as taste, enjoyment and food and mood enhancement, as well as symbolic reasons like self-esteem or others such as the social image derived from consuming it(Charters and Pettigrew, 2008).

This multiplicity of actors affects each market in different ways; thus, market segmentation is required in order to obtain cross-cultural results in each of them. Europe has a distinct behaviour based on the global lifestyle of society (Ferraris et al., 2020). This style is based on Young and Rubican's 4C's (Cross Culture, Consumer Characteristics: lifestyles, opinions, interests, and consumer behaviour patterns) (Szawacck-Mokrzycka, 2015), which justifies the differentiated study for this area of consumer attitudes and patterns.

Based on the microeconomic behavioural underpinnings of rational consumers, who maximise individual utility considering the available information and objective and subjective constraints they encounter, the study of price or willingness to pay for wine and its determinants has been the subject of extensive research, focused on two literature streams: the hedonic price function, and the willingness to pay. The hedonic pricing model is based on Lancaster's approach and assumes that the observed wine price is a function of various objective and subjective attributes or characteristics analysed by consumers when making a buying decision (for an in-depth literature review of empirical studies Outreville and Le Fur, 2020). The other branch of literature quantifies the price, through the willingness to pay, with consumer behaviour being influenced by both the objective and subjective attributes of wine and socio-economic characteristics.

In this context, changes in the economic and/or social environment can alter consumption patterns and motivation. Irrespective of their origin, crises affect consumer behaviour. This is the case for both economic and financial crises (Gabriela, 2010; Perriman et al., 2010; Mansoor and Jalal, 2011) and the current crisis caused by the Covid-19 pandemic (Loxton et al., 2020).

The objective of this study is an analysis of the changes that the Covid-19 lockdowns have brought about in terms of consumption patterns and wine expenditure in the Iberian market and of the multiple factors affected by these changes.

\subsection{The shock of lockdown on the spending on wine}

The Covid-19 pandemic has highlighted how exogenous risks from outside the wine sector can also cause substantial shocks in the industry, simultaneously impacting input markets, labour, 
logistics and consumer demand in unpredictable ways. The Covid-19 pandemic provides a stark example of how external adverse events can affect the wine industry. Although Covid-19 is fundamentally a public health issue, the disease has caused devastating impacts on the world economy - both directly and through measures to contain the spread of the virus. These consequences are increasingly spilling over into the wine market (Witwer and Anderson, 2020). There have been abrupt changes in the demand for wine, with ripple effects for supply chain design in the short-run and certainly in the long run. On the other hand, the traditional consumption channels such as restaurants and open markets were closed in response to government measures to deal with the pandemic. This resulted in the overnight collapse of demand for some niche and high-value wines and subtle changes in consumer behaviour and attitudes, namely in the type of wine purchased, the level of utility and, consequently, in the price consumers are willing to pay.

Consumer spending depends on many exogenous and endogenous factors, which can be affected by a crisis (Kotler and Armstrong, 1999). These include confidence (Ludvigson, 2004), personality (Tsao and Chang, 2010; Matz and Gladstone, 2016; Ebert et al., 2020), the psychological impact (Grohol, 2020; Mehta et al., 2020) and the social utility of the expenditure (Orth et al., 2005).

One of the aspects affected in a crisis is the composition of spending, both due to the change in the quantity purchased and the price paid for the different goods and services included in the shopping basket (Coibion et al., 2020; Andersen et al., 2020).

With this theoretical background, in order to analyse the changes in wine spending during the pandemic, the main hypothesis to test is:

\section{H.1. The lockdown influences the probability that a consumer is willing to spend more or less (compared to the usual spending) to buy a bottle of wine.}

\subsection{Changes in consumption patterns}

One of the factors explaining the variation in consumer spending is their perception of the hedonic and utilitarian value of their purchases (Babin et al., 1994). In the case of food, there are purchases more oriented towards pleasure and others towards the nutritional value of the products (Maehle et al., 2015); although the hedonic or utilitarian value may vary depending on the circumstances of the moment of consumption (Okada, 2015; Dhar and Wertenbroch, 2000). For example, some consumers prefer making hedonic purchases even though they are less healthy (Cramer and Antonides, 2011).

Wine drinking frequency and wine price are the relevant variables when it comes to understanding consumption patterns. Regular wine consumers drink substantially more than the country median (Bruwen and McCutcheohn, 2017). The impact of Covid-19 on consumption frequency is significant as it is a crucial aspect in defining consumption patterns (Rebelo et al, 2021). This leads us to formulate the following sub-hypothesis:

$H$ 1.1. The frequency of wine consumption before lockdown directly and positively affected the probability of a variation in the price paid for a bottle of wine during the lockdown. 
It is not possible to explain the changes in wine consumption without including the impact of substitute beverages (beer and spirits). Traditionally, there is a concentration of consumers at the national level for each type of beverage depending on country-specific cultural aspects (Ferraris et al. 2020), and a convergence between the different countries towards a global average mix of alcoholic consumption having been observed (Wittwer and Anderson, 2020). Given that these are substitute beverages, it is to be expected that the behaviour in their consumption frequency will have a direct and inverse relationship. That is, an increase in the frequency of consumption of substitute beverages will lead to a reduction in the probability of modifying the price paid for a bottle of wine. Based on this statement, it is possible to formulate the following sub-hypothesis

$H$ 1.2. The consumption of alcoholic beverages during the lockdown, particularly alternative products such as beer or spirits, directly and inversely affected the probability of a modification in the price paid for a bottle of wine.

\subsection{Changes in procurement patterns}

Changes affect the different products in different ways and can vary over time if the crises are prolonged (Zurawicki and Braidot, 2005); they can even condition long-term behaviour even after the crises have been overcome (Zwanka and Buff, 2020). In the early phases, changes are usually made towards cheaper goods, reducing consumer spending (Kaytaz and Gul, 2014). In the case of the Covid-19 crisis in the United Kingdom, Chronopoulos et al. (2020) observed an increase in grocery spending associated with panic buying during the two weeks following the announcement by the World Health Organisation (WHO) that Covid-19 was a pandemic and there was a reduction in spending between January and June 2020. A similar result was observed in Denmark and Sweden (Andersen et al., 2020) and the United States (Coibion et al., 2020), with a reduction above the average in textiles and travel.

$H$ 1.3. The willingness to purchase through different channels was modified due to the lockdown and diversely affected the probability of a change occurring in the price paid for a bottle of wine.

\subsection{Psychological and demographic aspects}

The case of wine is exciting, as, although the hedonic values are considered to be more prevalent, it has been observed that the preference for certain wines over others depends on the segmentation of the market between consumers who base their decision on price and others who do so on quality (Habban et al., 2018). Some studies identify a segmentation of wine consumers related to what is defined as Wine Related Lifestyle segmentation (WRL), describing the shopping methods, drinking occasions, consumption scenarios, expected consequences and quality attributes (Yabin and Li, 2020). 
In any event, in extreme circumstances, such as the Covid-19 crisis, with lockdowns of different severities and measures restricting social activities, the difference between hedonic and utilitarian purchases becomes more perceptible (Choi et al., 2020). Among the recent studies based on this approach, Yang et al. (2020) find that the latter has grown more; however, in the case of online food shopping in Turkey, Ozturk (2020) finds that the perception of a potential threat to life is positively related with both the utilitarian and hedonic value of the purchase.

Within this context, we would expect changes in the WRL to have taken place during the lockdown caused by the pandemic, together with a reduction in spending on wine, associated, in general, with a decrease in the price of the type of wine purchased. However, this association depends on several of the factors analysed.

$H$ 1.4. The lockdown modified wine consumption situations and the probability of a change in the price paid for a bottle of wine.

Wine consumption has a clear symbolic component: it establishes our position in society or our social path by relating it to our lifestyle or our self-image. One of the key motives for wine consumption, enjoyment, is independent of gender, age or level of interest in the product (Charters and Pettigrew, 2008). In this context, lockdown, which limits the social component and catering related consumption has led to substantial changes in consumption patterns and willingness to pay for a bottle of wine.

In addition, it has been shown that the composition of spending is affected by the expectations regarding the evolution of the crisis (Garner, 1991) and by the unemployment this causes (Ganong and Noel, 2015). Concerning the psychological impact, so-called panic buying can arise when consumers accumulate stocks above their current consumption needs (Erdem et al., 2003). This occurred during the Covid-19 pandemic in many countries (Keane and Neal, 2021).

$H$ 1.5. Psychological and demographic aspects affected the probability of a change occurring in the price paid for a bottle of wine.

\section{Methodology}

\subsection{Sample and variables}

Data collection is carried out through surveys, discrete choice experiments and economic experiments and the estimation is made through discrete choice models (Lockshin and Corsi, 2012). Both approaches are applied assuming the rational behaviour of consumers and with complete information, which may not be the case in abnormal situations such as the Covid-19 pandemic.

This study uses data previously collected by researchers from the board of the European Association of Wine Economists and the INSEEC - School of Business and Economics of the 
University of Bordeaux, and it was designed to explore the effects of the Covid-19 pandemic on alcohol consumption (https://www.euawe.com/). The survey was administered in four countries (France, Italy, Portugal, and Spain) between 17 April and 10 May 2020 through the SurveyMonkey platform. Four groups of questions were included in the survey: i) patterns of purchase and consumption; ii) consumption situation; iii) feelings and emotions during the lockdown; and iv) socio-demographic information.

The data collection process used the exponential discriminatory snowball sampling technique. This process has the advantage of guaranteeing rapid collection of data, which was a key feature regarding the duration of lockdowns. However, being a nonprobability technique, it may induce sampling bias (Dubois et al., 2020), since selection is not entirely random. This drawback tends to be reduced as the sample size increases (Taherdoost, 2016), but the results may not be entirely representative of the population of interest.

Acknowledging this, the universe of interest for this study can be defined as the population aged 18 years and over (i.e., representing possible wine consumers). All responses were anonymous, and to avoid restrictive answers (due to possible sensitive questions such as age or spending), the scale and methodology of the European Social Survey were used. Thus, the data collection process resulted in a sample of 4489 observations (2549 Spanish respondents and 1940 Portuguese respondents), which in this study is assumed to be representative of the population of interest of both countries ${ }^{1}$.

Since the goal of this study is to analyse the impact of consumer behaviour and the probability of change occurring in the average spending on a bottle of wine, comparing the lockdown period with the normal consumption situation or pre-lockdown in the Iberian market. Table 1 presents the list and scale of the explained and explanatory variables and the frequencies for each variable to be used in the econometric model to be estimated. The variables classified as " Change" were calculated as the difference between a value for the lockdown situation and the same value before the lockdown. After this step, the explained variable was normalised assuming three alternative categories (1 - negative difference, representing a decrease, 2 - a null difference, representing the " no change" situation, 3 - positive difference, representing an increase in the variable). This method of calculation affects the determination of the dependent variable.

Next, the same procedure was applied to other explanatory variables, such as changing procurement patterns or some consumption pattern situations. However, to reduce the number of variables, they were normalised as binary variables, where 1 reports a variation (positive or negative) from a typical situation in the lockdown period, and 0 represents " no change". The rest of the variables are binary, and their measurements are shown in Table 1 as frequencies.

Concerning the sample analysed, $60.5 \%$ of the respondents were male, $57 \%$ lived in urban areas, and $91.7 \%$ were employed. Almost $30 \%$ were aged between $41-50$ years, $26 \%$ between $51-60$, $17.6 \%$ belong to the $20-40$ years age range, $13.8 \%$ to the $61-70$ years age range, $9 \%$ were younger than 30 years old, and $4 \%$ were over 70 years old. More than $66 \%$ of the respondents reported

\footnotetext{
${ }^{1}$ According to the Instituto Nacional de Estadística (www.ine.es), accessed on 28 December 2020, the +18 years population in Spain was 36.011 .970 and in Portugal 8.353 .602 (www.pordata.pt, accessed on 28 December 2020). Thus, given our number of respondents, it is possible to build a $99 \%$ confidence interval, with an error margin of $2.60 \%$, to ensure representativeness of the sample.
} 
that they spent the same amount of money on buying a bottle of wine during the lockdown as they had done under normal conditions. Only $5 \%$ affirm that they purchased more expensive wine, and $28.6 \%$ spent less than in a normal situation. More than $48 \%$ of the respondents' report that they consumed less of each alcoholic beverage. However, in the case of wine, there is a higher percentage (34.5\%) indicating that they consumed more when compared to beer and spirits. The majority of the sample confirmed that they consumed wine at least once a week or daily. Almost $70 \%$ of the sample consumed wine because they like the taste and because wine pairs well with food, followed by socialising with friends (36\%). $27.7 \%$ have a wine app on their smartphone, and $46 \%$ received online wine offers during the lockdown. Regarding the change in procurement patterns for wine due to the lockdown situation, we can observe an increase in the online purchases for wine and private cellars. At the same time, demand through the other channels decreased. In terms of changes in consumption situation patterns, as expected, due to the lockdown measures, drinking wine alone and in digital meetings increased while consumption in social settings decreased.

\section{Insert Table I about here}

\subsection{Method}

The method used to analyse consumer choice and to estimate the effects of the independent variables on the probability of changing wine expenditure is based on the random utility theory, which assumes that, regardless of the setting and restrictions on decisionmaking, the consumer behaves in a way that maximises utility, given a set of choices. Specifically, when making a choice, it is assumed that individuals select the alternative that gives the highest utility (McFadden, 1974), such that:

$$
U(\text { choice } j)>U(\text { choice } q) \forall j \neq q
$$

where the perceived utility can be expressed as the sum of a deterministic component $\left(V_{j}\right)$ with a random component $\left(\varepsilon_{j}\right), U_{j}=V_{j}+\varepsilon_{j}$. The observed outcome variable is $\mathrm{Y}$, the index of the observed choice.

The econometric model describing $\mathrm{Y}$ is built around the assumption of the random elements in the utility function, such that, in general terms:

$$
\operatorname{Prob}(Y=j)=\operatorname{Prob}(U(\text { choice } j)>U(\text { choice } q) \forall j \neq q)
$$

For instance, when the willingness to pay off a consumer changes for a good (in our case, the average spending per bottle of wine), he or she is making a decision that probably maximises the utility. At the same time, the individual decision is influenced by psychological, behavioural, demographic and sociological variables that econometrically work as explanatory variables.

For the econometric modelling of consumer behaviour and for $Y$ with two or more measurement levels or categories, where the estimate for the parameter can be identified compared to a baseline category, the estimation of a multinomial logistic regression model is recommended (Greene, 2003). Other papers, such as Cacchianelli et al. (2016), also use logit regression to identify the multiple factors about wine consumption. This is the case of this research, which applies the multinomial logistic regression model to predict the probabilities of different possible outcomes (M) of a dependent variable, $Y$. 
Specifically, let $Y$ denote a categorical variable with more than two possible categories $\{1, \ldots, M\}$, here the expenditure variable with $\mathrm{M}=3$, which results in $\mathrm{M}-1$ equations, one for each category relative to the reference category, and let $x$ denote a set of explanatory variables. As usual, $\left(x_{1}, y_{1}\right)$ is a random draw from the population. The choice probability of each category $m$ is calculated as:

$$
P(Y=m)=\frac{e^{x \beta_{m}}}{1+\sum_{m=1}^{M} e^{x \beta_{m}}}, \quad m=1, \ldots, M
$$

and for the reference category, in this case, "2 - as usual":

$$
P(Y=2)=\frac{1}{1+\sum_{m=1}^{M} e^{x \beta_{m}}}
$$

where $\beta m$ is the $\mathrm{K} \times 1$ vector of unknown parameters and $x$ the $1 \times \mathrm{K}$ vector with the firstelement being unity. The model in (3) is the multinomial logit model (Nerlove and Press, 1973).

Additionally, taking the quotient between (3) and (4), the odds of each category concerning the reference category are given by:

$$
\frac{P(Y=m)}{P(Y=2)}=e^{x \beta_{m}}
$$

Therefore, applying a logarithm to both sides results in the following multi-equation model:

$$
\ln \frac{P(Y=m)}{P(Y=2)}=x \beta_{m}
$$

The model's parameters are estimated through the maximum loglikelihood method.

Additionally, the ratio given by (5) is commonly referred to as the relative isk. Thus, exponentiating the multinomial logit coefficients gives the relative-risk ratio (RRR) for a one-unit change in the corresponding variable $x$ :

$$
\mathrm{RRR}=\frac{P(Y=m \mid x+1) / P(Y=2 \mid x+1)}{P(Y=m \mid x) / P(Y=2 \mid x)}
$$

Risk refers to the risk of the alternative chosen relative to the base alternative. In general, if the $R R R<1$, the outcome is more likely to be in the referent category.

\section{Results}

The model is applied to test the main research hypothesis that some variables influence the probability that consumers were willing to spend more or less (compared to the usual spending) to buy a bottle of wine during the lockdown and the five secondary hypotheses.

Given that the sample comprises data from Portugal and Spain, structural differences tests between the countries were previously performed to decide whether to conduct a joint or separate analysis. The results from the likelihood ratio test do not suggest the existence of structural differences between the samples. Therefore, the analysis is performed for the Iberian market as a whole. Table 3 shows the estimation results for the multinomial logit regression model, following a stepwise approach that only retains the explanatory variables with regression coefficients that are statistically significant for one and/or both categories. 
4.1. The role of the variable spending of wine during the lockdown

Given the value of the Chi-square associated with the Likelihood Ratio (LR) test, the model is globally statistically significant, despite the difference in the 'parameters' significance between the two categories under analysis relative to the base category. This means that, in general, the variables included in the analysis were shown to influence the first category, i.e., the relative probability of spending less $(28.6 \%)$ on a bottle of wine rather than the usual amount. In the other category (higher spending, 5\%), they are not statistically significant, except for six variables, which is probably explained by the fact that a large number of people reported spending less on wine during the lockdown.

\section{Insert Table II about here}

A detailed analysis of the dependent variable enables us to enlarge on individual results referring to the significance of the change in average spending on a bottle of wine. The coding of the dependent variable has been carried out based on six categories: I do not buy wine; price <€5; $€ 5-10$; €11-20€; €21-30 and $+€ 30$. These ranges allow us to better understand the situation of change between the willingness to pay for a bottle of wine and also the number of steps between the two situations. A case where a consumer increases/decreases the price in a single range is not the same as one in more than one range.

Table 2 shows the details of the impact of this change by price range. We can conclude the variations by price range (number of steps of change) for increases and decreases.

$66.5 \%$ of the consumers did not make changes in the average price paid for a bottle of wine between the two periods. Among those who did modify the price, those consumers who reduced the price paid for a bottle of wine during the lockdown by between one and three steps for the standard period were the most frequent (27.3\%). Meanwhile, only $4.3 \%$ of them increased the price paid for a bottle and by only one step.

\subsection{The role of the variables describing the pattern consumption}

Among the variables included for analysis, we can observe different results for the probability that the price paid for a bottle of wine changed during the lockdown. Therefore, a high frequency of consumption before the lockdown negatively affects the probability of a reduced price paid for a bottle of wine during the lockdown. These consumers are considered more experienced and are not willing to pay a lower price, which enables us to confirm $\mathrm{H}$ 1.1.

\section{Insert Table III about here}

Regarding the consumption of alcoholic beverages during the lockdown, the substitution effect of beer and spirits is visible since consumers with a higher frequency of consumption of these beverages (beer and spirits) show a higher probability of having reduced their spending on wine. On the other hand, consumers showing increased frequency in wine consumption during the lockdown also offer a higher probability of having increased their spending on wine. The inverse relationship between the consumption of substitute products and the probability of an increase in spending on a bottle of wine enables us to confirm hypothesis H 1.2. 
The latter two results reflect the behaviour of a group of regular consumers of wine, in terms of consumption frequency, who, during the lockdown, increased both the frequency of their consumption and their probability of paying a higher price for a bottle of wine.

\subsection{The role of the variables describing the changes in the procurement pattern}

The analysis of the variables in the changes in procurement patterns group reveals that the shift in consumption of wine from own cellars is the principal factor affecting spending on a bottle of wine. People who changed (increase) their consumption from private cellars had a high probability of reducing their average spending on a bottle of wine. This case deserves particular attention as it reveals a relative probability of spending four times less than the corresponding probability for those who did not change their wine consumption from private cellars $\left(e^{1.504}=\right.$ 4.499). There was, therefore, a group of consumers who had sufficient wine stored to cover part of their consumption during the lockdown and who, when they had to purchase new stocks, were willing to pay a lower price for a bottle of wine to the price that they used to pay before the pandemic.

Concerning the rest of the supply channels, we can observe that those who reduced their purchases of wine in wine stores and wineries were more likely to spend less on a bottle of wine, as expected. This behaviour could be related to the individual rather than social consumption in the home and also to the fact that consumers did not want to purchase higher-priced wines that were before reserved for special occasions. The wine consumption pattern changed to become based on routines in a non-social environment, reducing the willingness to pay a high price for a bottle of wine.

Continuing the analysis of the changes in procurement patterns, the relative probability of higher than regular spending was higher among consumers who changed their wine purchasing in supermarkets, while the relative likelihood of spending less was more than double among the consumers who did not change their purchase in supermarkets $\left(e^{0.986}=2.689\right)$. Similar results for different consumption frequencies have been found in market segments referring to Millenials (Nassivera et al., 2020).

This duality in the significance of the variable indicates a behavioural profile differentiated in terms of the change in purchasing habits in supermarkets. One possible explanation is the difficulty for movement as a result of the Covid-19 restrictions. Therefore, it is probable that many consumers who usually purchased wine in specialised stores bought wine in supermarkets during the lockdown. In this case, we would expect that when normality resumes, those consumers with a higher probability of paying higher prices for a bottle of wine will return to the specialised stores. However, it will be necessary to confirm this behaviour and whether the supermarkets continue to supply wine in the high-price segment.

Regarding online purchasing, its coefficient is positive and statistically significant for higher spending compared to the normal level, indicating that the probability of spending more on a bottle of wine is more significant for people who increased their online wine purchase than for those who did not. The importance of online shopping can be viewed as a structural aspect, and wineries should take it into account in the future as part of their sales strategy. 
Finally, we should highlight the significance of the two digital variables in identifying consumers willing to increase the average amount they spend on a bottle of wine. The definition of digital strategies based on websites, apps and online sales will be vital for capturing these sales.

The results corresponding to procurement pattern changes enable us to validate hypothesis $\mathrm{H} 1.3$, given that behaviour varies depending on the channel. The emergence of online purchasing as a vehicle to increase the willingness to pay more money for a bottle of wine contrasts with the case of a wine store and wineries. Average spending was lower during the lockdown than in the previous normal situation.

\subsection{The role of the variables describing the psychological and demographics characteristics}

The analysis of consumption situation patterns, focusing on the psycho motives to drink wine, reveals that the relative probability of higher spending was $62 \%$ higher for those who drink wine for romance. The close probability of spending less than usual was $25 \%$ higher for the same people. The significance of both segments of spending on a bottle of wine could be due to the difference in consumer purchasing power. The higher-income segments were more willing to pay a higher price for a bottle, while the contrary was true for the lower-income consumers.

The reasons for drinking wine "to pair it with food", "I like the taste", and "it helps me relax" would decrease the relative probability of spending less on a bottle of wine.

Concerning the change in the different spheres of consumption, the decrease in consumption of wine with family and friends resulted in a higher probability of spending lower amounts on wine than the usual spending. This reveals the importance of the social context for wine consumption and the reduction of social gatherings negatively affected wine purchase behaviour.

Additionally, those who have a wine app installed on their smartphones are more likely to spend more on a bottle of wine, which is related to the consumer's engagement with wine consumption, i.e., consumers who are more interested in wine (thus have an app) are more likely to have increased their spending during the lockdown than those consumers who are less engaged.

The relevance of technology for purchasing wine and the probability of increasing average spending on a bottle of wine should lead companies to reflect on the importance of the digital field as a sales strategy, particularly for the highest price segments.

Hypothesis H1.4 is partially confirmed as we can observe behavioural changes in terms of consumption and price, which should be included in the strategies of wineries for higher-priced wines. Regarding demographic factors (control variables), only the place of residence affected expenditure on wine. Results for urban residence relative to non-urban suggest that people living in urban areas are more likely (27.5\%) to spend more on a bottle of wine than usual, and $13.5 \%$ are more likely to spend less than usual, compared to non-urban residents.

Finally, the positive and statistically significant sign of the coefficient for fear of crisis implies that the probability of spending less than usual on wine increases as the fear of an economic crisis due to Covid-19 increases (Accept H1.5). In this case, when these reasons for consuming wine predominate, there is a propensity to reduce spending as these motivations are not related to hedonic reasons. 


\section{Discussion and Conclusions}

Based on a large sample of Iberian consumers, this study is the first of its kind to explore the behaviour of wine consumers during the lockdown, with a focus on the factors affecting the propensity to spend more or less on a bottle of wine compared to a normal situation (before Covid-19). This research constitutes a first step to understanding the expenditure of wine consumers during an abnormal situation, such as the Covid-19 pandemic. This is useful to understand the key factors influencing choices and which factors affect the propensity to spend on a bottle of wine.

\subsection{Theoretical implications}

The study of the impact of lockdowns on willingness to pay for a bottle of wine is a distinct element in the framework of consumer behaviour analysis. It is necessary to consider that the theoretical implications derived from an isolated event may not be trend generating in terms of consumption patterns.

Other unusual events such as crises, earthquakes and other natural disasters have also been analysed and it has been observed that all of the consumption patterns have quickly recovered. In the case of financial crises, given their cyclical patterns, it has been possible to identify the changes before, during and after them (Garbinti et al., 2020).

However, the distinctive nature of this work is related to the uniqueness of the event concerned and the fact that its impact has not yet ended. The long duration of the Covid-19 pandemic is causing changes in consumption that started during the lockdown and that will need to be followed up in order to analyze their duration as new consumption patterns.

The first theoretical implication is related to the changes that the coronavirus has caused in alcohol drinking habits. Consumers generally spent less on wine during the lockdown, maybe due to the uncertainty about their future income and professional situation. Several variables were shown to influence the probability of spending less on wine, while only six factors were found to be determinants for higher spending. In this way, we have confirmed hypothesis H1 as changes in procurement and consumption patterns during the lockdown have influenced the probability to spend more or less (compared to the usual spending) on a bottle of wine during the lockdown.

There is a second issue related to the continuity of changes in purchasing patterns. The literature has revealed the importance of finding the reasons behind wine consumption (WRL) and the impact of technology on purchase channels. Our findings suggest that people with a higher probability of spending more on wine increased their wine consumption frequency during the lockdown. These consumers drank for romance purposes, those who purchase less wine in supermarkets but more online, those who use a wine app, and those living in urban areas. Regarding the probability of spending less on wine than a normal situation, the principal factor is the increased consumption of wine from private cellars. This can be explained due to lockdown restrictions. Consumers decreased their purchases in traditional channels (due to the fear of being infected or even because the establishments were closed) and preferred to consume wine from their private stock. Increasing consumption of other alcoholic beverages also increased the probability of spending less than usual on wine. Additionally, the reasons for drinking wine other than for social purposes, such as wine and food pairing, its taste and relaxing effects and previous consumption patterns led to a decrease in the probability of spending less per bottle. 
As the epidemiological situation of the new coronavirus required some political response measures, such as "stay home, stay safe" directives and people practising social distancing, the changes in consumption with family and friends produced the expected result, a higher probability of spending less than usual on wine. In the same way, the fear of crisis impacts the spending intentions of households, so the fear arising from the pandemic has led to consumers spending less than usual on a bottle of wine. This will be a question to be analysed as confinement measures are relaxed. It will be at that point when it will be possible to study whether changes in place of consumption or social distance are here to stay as a lifestyle change (WRL) or whether there will be a return to the pre-pandemic situation in whole or in part.

\subsection{Managerial and policy implications}

The findings show that managers and policymakers (especially the regulatory entities from the sector) should pay attention to the different influences of variables related to behaviour and consumption patterns that may increase the demand for less expensive wines. Specifically, they should focus on new consumption patterns that may arise to adapt the supply chain and define appropriate marketing strategies to fill new market segments.

We can identify two consumer profiles crucial for understanding how the consumer and spending patterns were modified during the lockdown. Table 4 includes these results. Therefore, it is possible to identify a profile called incoming consumers, corresponding to those consumers/purchasers who did not buy wine in the normal period and who, however, purchased bottles of wine during the lockdown. In this case, we can observe how there were only 18 new wine consumers, representing the entry into the sector of $0.4 \%$. This is a key aspect as it reveals that new wine consumers were not captured during the lockdown. As additional information, we can observe that the most popular price range per bottle for incoming consumers was the $€ 5-10$ range, followed, with the same frequency, by the lower prices $(<€ 5)$ and then the €20-30 range which is considered as high.

The other type of profile corresponds to the outgoing consumers. These are consumers who usually consume wine but did not buy any bottles during the lockdown. This group was made up of 832 consumers (19.2\%). We can observe a greater distribution across the outgoing price ranges than in the previous case. Table 4 shows that the consumers who stopped buying wine did so first in the lower price ranges, with the proportion decreasing as the price per bottle increased. The greatest impact can be observed among outgoing consumers of wine in the $<€ 20$, falling drastically for higher ranges. We would need to confirm whether the consumers who stopped buying wine did so because they were consuming wine that they had stored at home or because they had indeed stopped consuming wine.

\section{Insert Table IV about here}

\subsection{Limitations and future research}

This study has some limitations. First, the sampling method (snowball sampling technique) is a nonprobability method, which can induce sample bias, since the respondents were not selected by an entirely random process, thus the sample is not stratified. Thus, the sociodemographic characteristics of the respondents may not match those officially reported concerning the country-wide populations (of wine consumers). Second, such differences may be reflected in the 
interpretation of the results, which represent a limitation in the generalization of the findings, since representativeness of the true population of interest cannot be guaranteed. Following this, further research could benefit from the use of other sampling techniques, namely probabilistic sampling techniques, to ensure the true representativeness of the results.

Furthermore, this study was carried out in a very abnormal situation and not comparable to a "normal" context, such that, for further research, including psychological factors that could explain wine consumption changes during a crisis, such as the Covid-19 pandemic, might be key to a broader understanding of the spending shocks. Additionally, it would be interesting to conduct a more in-depth analysis of whether the purchaser/consumer profiles have remained the same after the lockdown period.

Moreover, it is necessary to create loyalty among the incoming consumers and maintain their interest, and to study whether the outgoing consumers are returning to the sector or whether they have been lost definitively. Furthermore, it may be possible to identify profiles of spending on a bottle of wine before and after the lockdown regarding segmentations according to the type of consumer (Bruwer and Li, 2007; Bruwer and Li 2017 Yabin and Li, 2020).

\section{References}

Andersen, A. L., Hansen, E. T., Johannesen, N., and Sheridan, A. (2020). "Pandemic, shutdown and consumer spending: Lessons from Scandinavian policy responses to COVID-19". arXiv preprint arXiv:2005.04630.

Anderson, K. and Pinilla, V. (Eds.) (2018). Wine Globalization. A New Comparative History. Cambridge University Press, New York.

Arpaci, I., Karatas, K. and Baloglu, M. (2020). "The development and initial tests for psychometric properties of Covid-19 Phobia Scale (C119-PS)". Personality and Individual Differences, May 2020 (available online)

Babin, B. J., Darden, W. R., and Griffin, M. (1994). "Work and/or fun: measuring hedonic and utilitarian shopping value". Journal of consumer research, 20(4): 644-656.

Bor, J., Basu, S., Coutts, A., McKee, M., and Stuckler, D. (2013). "Alcohol Use During the Great Recession of 2008-2009". Alcohol, 48(3): 343-348.

Bruwer, J. and Li, E. (2007): "Wine-related lifestyle (WRL) market segmentation: demographic and behaviour factors". Journal of Wine Research, 18 (1):19-34

Bruwer, J. and Li, E. (2017): "Domain-specific market segmentation using a latent class mixture modelling approach and wine-related lifestyle (WRL) algorithm". European Journal of Marketing, 51 (9): 1552-1576.

Cacchiarelli, L.; Carbone, A.; Esti, M.; Laureti, T. Sorrentino, A. and Griffith, C. (2016) : Assessing Italian wine quality and prices: de gustibus non disputandum est. British Food Journal, 118 (5); $1-20$

Charters, S. and Pettigrew, S. (2008): Why do people drink wine? A Consumer-focused exploration. Journal of Food Products Marketing, 14 (3): 13-32. 
Choi, J., Madhavaram S. and Park Hyun Young (2020). "The Role of Hedonic and Utilitarian Motives on the Effectiveness of Partitioned Pricing". Journal of Retailing, 96 (2):251-265.

Chronopoulos, D. K., Lukas, M., and Wilson, J. O. (2020). "Consumer spending responses to the COVID-19 pandemic: an assessment of Great Britain". Centre for Responsible Banking and Finance Working Papers in Responsible Banking and Finance, No.20-012.

Coibion, O., Gorodnichenko, Y., and Weber, M. (2020). The cost of the covid-19 crisis: Lockdowns, macroeconomic expectations, and consumer spending. National Bureau of Economic Research, (No. w27141).

Cramer, L., and Antonides, G. (2011). "Endowment effects for hedonic and utilitarian food products". Food quality and preference, 22(1): 3-10.

Dhar, R., and Wertenbroch, K. (2000). "Consumer choice between hedonic and utilitarian goods". Journal of marketing research, 37(1): 60-71.

Dubois, M.; Agnoli, L.; Cardebat, J.M.; Compés, R.; Faye, B.; Frick, B.; Gaeta, D.; Giraud-Héraud,

E.; Le Fur, E.; Livat, F.; Malorgio, G.; Masset, P,; Meloni, G.; Pinilla, V.; Rebelo, J.;Rossetto, L.; Schamel, G. and Simon-Elorz, K. (2021). "How did wine consumption evolve during the Covid-19 lockdown in Europe". Journal of Wine Economics (In press).

Ebert, T., Götz, F. M., Gladstone, J. J., Müller, S. R., and Matz, S. C. (2020). "Spending reflects not only who we are but also who we are around: The joint effects of individual and geographic personality on consumption". Journal of Personality and Social Psychology, Advance online publication. https://doi.org/10.1037/pspp0000344.

Erdem, T., Imai, S. and Keane, M.P. (2003). "Brand and quantity choice dynamics under price uncertainty". Quantitative Marketing Economics, 1 (1): 5-64.

Ferraris, A.; Del Giudice, M.; Grandhi, B. and Cillo, V. (2020) Refining the relation between cause-related marketing and consumer purchase intentions. A cross-country analysis. British Food Journal, 37 (4): 651-669. Forbes, S. L. and Wilson, M. M. (2018). "Resilience and response of wine supply chains to disaster: the Christchurch earthquake sequence". International Review of Retail, Distribution and Consumer Research, 28(5): 472-489.

Gabriela, S. (2010). "Changes in consumer behaviour during an economic crisis". Ovidius University Annals, Economic Sciences Series, 10(2): 784-787.

Ganong, P., and Noel, P. (2015). "How does unemployment affect consumer spending?" Unpublished manuscript, Harvard Univ., Cambridge, MA. http://scholar. Harvard. edu/files/ganong/files/ganongmpnemploymentpending. pdf Article Location.

Garbinti, B.; Goupille-Lebret, J. and Piketty, T. (2020). "Accounting for wealth-inequality dynamics: methods, estimates, and simulations for France". Journal of the European Economic Association, 19 (1):620-663.

Garner, C. A. (1991). "Forecasting consumer spending: Should economists pay attention to consumer confidence surveys?". Economic Review, 76(3): 57-71.

Gergaud, O., Livat, F. and Song, H. (2018). "Terrorism and wine tourism: The case of museum attendance". Journal of Wine Economics, 13(4): 375-383.

Greene, W (2003). Econometric Analysis. Macmillan, New York. 
Grohol, J. (2020). "Panic buying: The psychology of hoarding toilet paper, beans and soup". Psych Central. https://psychcentral.com/blog/panic-buying-the-psychology-of-hoarding-toiletpaper-beans-soup (accessed 12 March 2021)

Habann, F., Zerres, C., and Zaworski, L. (2018). "Investigating the segment-specific preferences for hedonic and utilitarian online-shop characteristics: the case of German online wine shops". International Journal of Internet Marketing and Advertising, 12(3): 255-269.

Kaytaz, M., and Gul, M. C. (2014). "Consumer response to economic crisis and lessons for marketers: The Turkish experience". Journal of Business Research, 67(1): 2701-2706.

Keane, M., and Neal, T. (2021). "Consumer panic in the COVID-19 pandemic". Journal of econometrics, 220(1): 86-105.

Kotler, P. and Armstrong, G. (1999). Principles of Marketing, 8th ed., Prentice-Hall, Upper Saddle River, NJ.

Lockshin, L., and Corsi, A. M. (2012). "Consumer behaviour for wine 2.0: A review since 2003 and future directions". Wine Economics and Policy, 1(1): 2-23.

Loxton, M., Truskett, R., Scarf, B., Sindone, L., Baldry, G., and Zhao, Y. (2020). "Consumer behaviour during crises: preliminary research on how coronavirus has manifested consumer panic buying, herd mentality, changing discretionary spending and the role of the media in influencing behaviour". Journal of Risk and Financial Management, 13(8): 166.

Ludvigson, S. (2004). "Consumer confidence and consumer spending". Journal of Economic Perspectives, 18(2): 29-50.

Mansoor, D., and Jalal, A. (2011). "The global business crisis and consumer behaviour: the Kingdom of Bahrain as a case study". International Journal of Business and Management, 6(1): 104.

Maehle, N.; Iversen, N.; Hem, L. And Otnes, C. (2015). "Exploring consumer preferences for hedonic and utilitarian food attributes". British Food Journal, 117(12): 3039-3063.

Matz, S.; Galdstone, J. And Stillwell, D. (2016). "Money buys happiness when spending fits our personality". Psychological Science, 27 (5): 715-725.

McFadden, D. (1974). Conditional logit analysis of qualitative choice behaviour. Z. P (Ed.), Frontiers in Econometrics. Academic Press, New York, pp. 105-142.

Mehta, S., Saxena, T., \& Purohit, N. (2020). The New Consumer Behaviour Paradigm amid COVID19: Permanent or Transient? Journal of Health Management, 22(2), 291-301.

Nassivera, F.; Gallenti, G. Troiano, S. ; Marangon, F. ; Cosmina, M ; Bogoni, P. ; Campisi, B. ; and Carzedda, M. (2020) : "Italian millennials' preferences for wine: an exploratory study". Bristish Food Journal, 122 (8): 2403-2423.

Nerlove, Marc and S. James Press (1973) Univariate and multivariate log-linear and logistic models, R-1306-EDA/NIH, Santa Monica: Rand, available at http://www.rand.org/pubs/reports/2006/R1306.pdf.

Okada, E. (2005). "Justification effects on consumer choice of hedonic and utilitarian goods". Journal of Marketing Research, XLII (1): 43-53. 
Orth, U. R., Wolf, M. M., and Dodd, T. H. (2005). "Consumer personality and other factors in situational brand choice variation". Journal of Product \& Brand Management, 13:115-133.

Outreville, J-F. and Le Fur, E. (2020). "Hedonic Price Functions and Wine Price Determinants: A Review of Empirical Research", Journal of Agricultural and Food Industrial Organization, 18 (2): 1-27.

Ozturk, R. (2020). "Health or Death? The online purchase intentions of consumers during the COVID-19 pandemic. Transnational Marketing Journal, Transnational Press London, UK, 8(2): 219-241.

Peighambari, K.; Sattari, S.; Kordestani, A. and Oghazi, P. (2016): Consumer behavior research:

A synthesis of the Recent Literature. SAGE Open, April-June: 1-9.

Perriman, H. E., Ramsaran-Fowdar, R. R., and Baguant, P. (2010). "The impact of the global financial crisis on consumer behaviour". The 2010 Annual London Business.

Rebelo, J., Compés, R., Faria, S., Gonçalves, T. Pinilla, V. and Simón-Elorz, K. (2021). "Covid-19 Lockdown and Wine consumption frequency in Portugal and Spain", Spanish Journal of Agricultural Research, forthcoming.

Szwaccka-Mokrzycka, J. (2015): Trens in consumer behavior changes. Overview of concepts. Acta Sci. Pol. Oeconomia, 14 (3): 149-156.

Taherdoost, A (2016). "Sampling Methods in Research Methodology; How to Choose a Sampling Technique for Research". International Journal of Academic Research in Management, 5(2), 18-27.

Tsao, W. and Chang, H. (2010). "Exploring the impact of personality traits online shopping behavior". African Journal of Business Management, 4(423): 1800-1812.

Witwer, G. and Anderson, K. (2020). "COVID-19 and Global Beverage Markets: Implications for Wine". Wine Economics Research Centre Working Papers 2020-01.

Wittwer, G. and Anderson, K. (2020): A model of global beverage markets. Journal of Wine Economics, 15 (3): 330-354.

Yabin, W. and Li, J. (2020): "Segmentation China's online wine market based on the wine-related lifestyle". British Food Journal, 122 (8): 2385-2401.

Yang, Y., Li, O., Peng, X., and Wang, L. (2020). "Consumption Trends During the COVID-19 Crisis: How Awe, Coping, and Social Norms Drive Utilitarian Purchases". Frontiers in psychology, 11.

Zurawicki, L., and Braidot, N. (2005). "Consumers during crisis: responses from the middle class in Argentina". Journal of Business Research, 58(8): 1100-1109.

Zwanka, R. And Buff, Ch. (2020). "COVID-19 Generation: a conceptual framework of the consumer behavioral shifts to be caused by the COVID-19 pandemic". Journal of International Consumer Marketing, 33(1): 58-67.The shock of lockdown on the spending on wine in the Iberian market: the effects of procurement and consumption patterns

Table I. Explained and explanatory variables 


\begin{tabular}{|c|c|c|c|c|c|}
\hline \multirow[t]{2}{*}{ Type of variable } & & \multicolumn{2}{|c|}{ Iberian market } & \multirow{2}{*}{$\begin{array}{c}\text { Portugal } \\
\% \\
\end{array}$} & \multirow{2}{*}{$\begin{array}{c}\text { Spain } \\
\%\end{array}$} \\
\hline & & $\mathbf{N}^{\Delta}$ & $\%$ & & \\
\hline Explained & Scale & & & & \\
\hline \multirow{3}{*}{$\begin{array}{l}\text { Change in the average spending on } \\
\text { a bottle of wine }\end{array}$} & 1- Lower & 1282 & 28.6 & 29.2 & 28.1 \\
\hline & 2- $\quad$ As usual & 2983 & 66.5 & 66.4 & 66.5 \\
\hline & 3- Higher & 224 & 5.0 & 4.4 & 5.4 \\
\hline \multicolumn{6}{|l|}{ Explanatory } \\
\hline \multicolumn{6}{|c|}{ Frequency of consumption of wine before the lockdown } \\
\hline \multirow{5}{*}{ Wine cons } & 1- Never & 147 & 3.3 & 2.9 & 3.5 \\
\hline & 2- Less than once a month & 359 & 8.0 & 7.9 & 8.1 \\
\hline & 3- At least once a month & 640 & 14.3 & 12.2 & 15.8 \\
\hline & 4- At least once a week & 1991 & 44.4 & 41.3 & 46.7 \\
\hline & 5- Daily & 1352 & 30.1 & 35.7 & 25.9 \\
\hline \multicolumn{6}{|c|}{ Consumption of alcoholic beverages during the lockdown } \\
\hline \multirow{3}{*}{ Lock_wine } & 1- less & 2167 & 48.3 & 52.9 & 44.7 \\
\hline & 2- as usual & 773 & 17.2 & 14.5 & 19.3 \\
\hline & 3- more & 1549 & 34.5 & 32.6 & 36.0 \\
\hline \multirow{3}{*}{ Lock_beer } & 1- less & 2194 & 48.3 & 53.4 & 45.4 \\
\hline & 2- as usual & 2140 & 47.8 & 38.6 & 54.6 \\
\hline & 3- more & 155 & 3.5 & 0.0 & 8.0 \\
\hline \multirow{3}{*}{ Lock_spirits } & 1- less & 2167 & 48.3 & 53.0 & 44.6 \\
\hline & 2- as usual & 2136 & 47.6 & 37.4 & 55.4 \\
\hline & 3-more & 186 & 4.1 & 9.6 & 0.0 \\
\hline \multirow{6}{*}{$\begin{array}{l}\text { Change in procurement } \\
\text { pattern } \\
\qquad(1=y e s)\end{array}$} & Change in supermarket & $986^{-}$ & 22.0 & 23.4 & 20.9 \\
\hline & Change in grocery & $389-$ & 8.7 & 5.2 & 11.3 \\
\hline & Change in cellar & $799+$ & 17.8 & 18.2 & 17.5 \\
\hline & Change in wine store & $1236^{-}$ & 27.5 & 26.4 & 28.4 \\
\hline & Change in online & $486^{+}$ & 10.8 & 11.0 & 10.7 \\
\hline & Change in winery & $988^{-}$ & 22.0 & 20.1 & 23.5 \\
\hline \multirow{15}{*}{$\begin{array}{l}\text { Consumption situation } \\
(1=y e s)\end{array}$} & Change in Cons Alone & $655^{+}$ & 14.6 & 15.2 & 14.1 \\
\hline & Change in Cons Family & $858^{-}$ & 19.1 & 16.8 & 20.9 \\
\hline & Change in Cons Friends & $3017-$ & 67.2 & 64.9 & 69.0 \\
\hline & Change in Cons Colleagues & $836^{-}$ & 18.6 & 20.1 & 17.5 \\
\hline & Change in Cons Digital & $715^{+}$ & 15.6 & 10.8 & 19.9 \\
\hline & Motive_taste & 3085 & 68.7 & 68.1 & 69.2 \\
\hline & Motive_relax & 1123 & 25.0 & 30.5 & 20.9 \\
\hline & Motive_food & 3033 & 67.6 & 76.1 & 61.0 \\
\hline & Motive_friendly & 1614 & 36.0 & 43.3 & 30.4 \\
\hline & Motive_health & 280 & 6.2 & 4.8 & 7.3 \\
\hline & Motive_sleep & 151 & 3.4 & 3.6 & 3.2 \\
\hline & Motive_challenge & 770 & 17.2 & 15.4 & 18.5 \\
\hline & Motive_romance & 418 & 9.3 & 9.1 & 9.5 \\
\hline & Wine app & 1243 & 27.7 & 34.5 & 22.5 \\
\hline & Received online offers & 2075 & 46.2 & 54.0 & 40.3 \\
\hline Fear of crisis (average) & $1=$ strongly disagree to $5=$ str & y agree & 4.4 & 4.4 & 4.4 \\
\hline \multicolumn{6}{|l|}{ Control } \\
\hline Gender & Male & 2718 & 60.5 & 61.9 & 59.6 \\
\hline \multirow{6}{*}{ Age } & $18-29$ & 403 & 9.0 & 11.1 & 7.3 \\
\hline & $20-40$ & 792 & 17.6 & 19.1 & 16.6 \\
\hline & $41-50$ & 1327 & 29.6 & 30.9 & 28.6 \\
\hline & $51-60$ & 1172 & 26.1 & 22.9 & 28.6 \\
\hline & $61-70$ & 618 & 13.8 & 11.6 & 15.4 \\
\hline & $>70$ & 177 & 3.9 & 4.4 & 3.6 \\
\hline Type of residence & Urban & 2560 & 57.0 & 50.1 & 62.3 \\
\hline Professional situation & Employed & 4118 & 91.7 & 86.6 & 95.6 \\
\hline
\end{tabular}

Note: $\Delta$ indicates the direction of variation in the variable from a normal situation (before lockdown) to the lockdown, where - represents a decrease and + an increase. 
Table II: Impact of change of spending on a bottle of wine by price range

\begin{tabular}{||c|c|c||}
\hline Situation & Count & Frequency \\
\hline No change & 2,983 & $66.5 \%$ \\
\hline \hline$\Delta 1$ step & 194 & $4.3 \%$ \\
\hline$\Delta 2$ step & 22 & $0.5 \%$ \\
\hline$\Delta 3$ step & 7 & $0.2 \%$ \\
\hline$\Delta 4$ step & 1 & $0.0 \%$ \\
\hline$\Delta 5$ step & 0 & $0.0 \%$ \\
\hline \hline $\boldsymbol{\nabla} 1$ step & 541 & $12.1 \%$ \\
\hline $\boldsymbol{\nabla} 2$ step & 444 & $9.9 \%$ \\
\hline $\boldsymbol{\nabla}$ 3 step & 236 & $5.3 \%$ \\
\hline $\boldsymbol{\nabla} 4$ step & 44 & $1.0 \%$ \\
\hline $\boldsymbol{\nabla}$ 5 step & 17 & $0.4 \%$ \\
\hline & 4,489 & $100 \%$ \\
\hline \multicolumn{2}{|r|}{}
\end{tabular}


Table III - Multinomial logit estimation results (reference category = as usual)

\begin{tabular}{|c|c|c|}
\hline \multirow{2}{*}{ Variable } & \multicolumn{2}{|c|}{ Spending on a bottle of wine } \\
\hline & Lower & Higher \\
\hline \multicolumn{3}{|c|}{ Frequency of consumption of wine before the lockdown } \\
\hline Wine cons & $-0.293(0.04)^{* * *}$ & $0.126(0.09)$ \\
\hline \multicolumn{3}{|c|}{ Change in frequency consumption of wine during the lockdown } \\
\hline Lock_wine & $-0.019(0.04)$ & $0.441(0.08) * * *$ \\
\hline Lock_beer & $0.113(0.04) * * *$ & $0.063(0.08)$ \\
\hline Lock_spirits & $0.131(0.04) * *$ & $0.010(0.08)$ \\
\hline \multicolumn{3}{|c|}{ Changes in procurement pattern } \\
\hline Change_supermarket & $0.986(0.09) * * *$ & $0.647(0.17) * * *$ \\
\hline Change_cellar & $1.504(0.09) * * *$ & $-0.281(0.26)$ \\
\hline Change_wine store & $0.482(0.09) * * *$ & $-0.167(0.16)$ \\
\hline Change_winery & $0.237(0.09) * * *$ & $0.100(0.17)$ \\
\hline Change_online & $-0.109(0.12)$ & $0.420(0.19) * *$ \\
\hline \multicolumn{3}{|c|}{ Consumption situation pattern } \\
\hline Motive_taste & $-0.215(0.09) * *$ & $0.069(0.17)$ \\
\hline Motive_relax & $-0.214(0-09) * *$ & $-0.024(0.16)$ \\
\hline Motive_romance & $0.249(0.14) *$ & $0.620(0.20) * * *$ \\
\hline Motive_food & $-0.242(0.08) * * *$ & $-0.172(0.16)$ \\
\hline Change_family & $0.492(0.09) * * *$ & $0.089(0.19)$ \\
\hline Change_friends & $0.314(0.086) * * *$ & $-0.043(0.16)$ \\
\hline Wine app & $0.025(0.09)$ & $0.372(0.15) * *$ \\
\hline Fear_crisis & $0.096(0.05) *$ & $-0.113(0.09)$ \\
\hline \multicolumn{3}{|l|}{ Sociodemographic } \\
\hline Urban & $0.135(0.07) *$ & $0.275(0.15) *$ \\
\hline Cons & $-1.208(0.29)^{* * *}$ & $-4.061(0.59) * * *$ \\
\hline Number of observations & \multicolumn{2}{|c|}{4489} \\
\hline Log likelihood & \multicolumn{2}{|c|}{-2998.1} \\
\hline LR Chi²(36) & \multicolumn{2}{|c|}{$998.4^{* * *}$} \\
\hline
\end{tabular}

Note: $* * *, * *$ and $*$ denotes significance at the $1 \%, 5 \%$ and $10 \%$ levels, respectively. Estimations through the stepwise approach, which dropped non-significant variables at the $10 \%$ level. Standard errors in parentheses; Base outcome for spending variable $=$ as usual. 
Table IV: New profiles of wine spending

\begin{tabular}{||c|c|c||c||}
\hline $\begin{array}{c}\text { Lockdown } \\
\text { expenditure per } \\
\text { bottle }\end{array}$ & $\begin{array}{c}\text { Normal expenditure } \\
\text { per bottle }\end{array}$ & Count & Frequency \\
\hline \hline \multicolumn{3}{|c||}{ Incoming (New entrants) = 18 (0.4\%) } \\
\hline$<5 €$ & Don't buy wine & 3 & $0.1 \%$ \\
\hline $5-10 €$ & Don't buy wine & 10 & $0.2 \%$ \\
\hline $11-20 €$ & Don't buy wine & 1 & $0.0 \%$ \\
\hline $20-30 €$ & Don't buy wine & 3 & $0.1 \%$ \\
\hline $30 €$ & Don't buy wine & 1 & $0.0 \%$ \\
\hline \hline \multicolumn{1}{||c||}{ Outgoing = 862 (19,2\%) } \\
\hline Don't buy wine & $<5 €$ & 167 & $3.7 \%$ \\
\hline Don't buy wine & $5-10 €$ & 407 & $9.1 \%$ \\
\hline Don't buy wine & $11-20 €$ & 228 & $5.1 \%$ \\
\hline Don't buy wine & $20-30 €$ & 43 & $1.0 \%$ \\
\hline Don't buy wine & $30 €$ & 17 & $0.4 \%$ \\
\hline
\end{tabular}

